\title{
Expression of p-Akt in Sensory Neurons and Spinal Cord after Peripheral Nerve Injury
}

\author{
Tie-Jun Sten Shi ${ }^{a}$ b Ping Huang ${ }^{a} \quad$ Jan Mulder ${ }^{a} \quad$ Sandra Ceccatelli ${ }^{a}$ \\ Tomas Hökfelt ${ }^{a}$

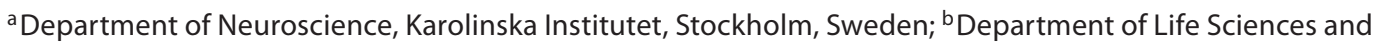 \\ Engineering, Bio-X Center, Harbin Institute of Technology, Harbin, China
}

\section{Key Words}

Dorsal root ganglion $\cdot$ Inflammation $\cdot$ Neuropeptide .

Nuclear translocation $\cdot$ Pain $\cdot$ Spinal cord

\begin{abstract}
Akt has been implicated in pro-survival and anti-apoptotic activities in many cell types, including dorsal root ganglion (DRG) and spinal motor neurons. In this immunohistochemical study we have monitored phosphorylated Akt ( $p-A k t)$ levels in adult mouse DRGs and spinal cord following unilateral peripheral sciatic nerve transection (axotomy) or carrageenan-induced inflammation. In control animals around half of the lumbar DRG neuron profiles (NPs), mainly small and medium-sized ones, were p-Akt immunoreactive (IR), and of these around $50 \%$ expressed calcitonin gene-related peptide and/or isolectin IB4. Two weeks after axotomy, the number of p-Akt-positive NPs was only slightly reduced, but p-Akt immunofluorescence intensity was strongly increased. One third of the ipsilateral p-Akt-IR NPs was galanin positive, but virtually without colocalization with neuropeptide $\mathrm{Y}$. Furthermore, p-Akt-like immunoreactivity significantly increased in intensity in the ipsilateral spinal dorsal horn after
\end{abstract}

This study is dedicated to Prof. Ji-Sheng Han on the occasion of his 80th birthday.
(C) 2009 S. Karger AG, Basel

$1424-862 X / 09 / 0173-0203 \$ 26.00 / 0$

Fax +41613061234 E-Mail karger@karger.ch www.karger.com
Accessible online at:

www.karger.com/nsg axotomy and expanded into deeper layers. Carrageenan-induced peripheral inflammation increased the number of $p$ Akt-IR NPs after $1 \mathrm{~h}$. Both axotomy and inflammation caused a clear increase in nuclear p-Akt-like immunoreactivity in DRG neurons. Our findings support a role for Akt as a key signaling molecule in sensory neurons and spinal cord after peripheral injury.

Copyright $\odot 2009$ S. Karger AG, Basel

\section{Introduction}

Primary sensory neurons synthesize a large number of signaling molecules involved in the transmission and modulation of nociceptive information from the peripheral to the central nervous system [1]. A well-known aspect of sensory neurons is the remarkable chemical plasticity following peripheral nerve injury [1-6], as also shown in more recent array studies [7-9]. Thus, after nerve injury the phenotype of sensory neurons is markedly changed, which may be important for regeneration/survival and development of neuropathic pain for example.

Akt, also known as protein kinase B, is a serine/threonine kinase with sequence homology to protein kinases $A$ and $C[10,11]$. As a key downstream substrate in the phosphatidyl-inositol 3-kinase (PI3-K) pathway, Akt plays important roles in various biological processes, in-

Dr. Tie-Jun Shi

Department of Neuroscience, Karolinska Institutet

SE-171 77 Stockholm (Sweden)

Tel. +4685248 7067, Fax +468331692

E-Mail tiejun.shi@ki.se or tiejun_shi@hit.edu.cn 
cluding intermediary metabolism, cell proliferation and differentiation, as well as cell survival [12-17]. In the nervous system, Akt has been investigated in various animal models under both physiological and pathological conditions, providing evidence for important roles in both the peripheral and the central nervous system. For example, the PI3-K/Akt pathway is involved in regulating neural plasticity in the brain [18-23]. Moreover, recent data indicate that Akt participates in nociceptive information processing through modulating the transduction of intracellular signals in dorsal root ganglions (DRGs) and spinal dorsal horn [24-27].

An important sequel of nerve injury and other nervous system diseases is neuronal degeneration and death. It is well known that neurotrophic factors can regulate neuronal cell survival and apoptosis [28-30]. Through activation of the Trk family of receptor tyrosine kinases, neurotrophic factors elicit various signaling cascades, including mitogen-activated protein kinase, PI3-K/Akt and phospholipase $\mathrm{C}$ [31-35]. Among these three pathways, PI3-K/Akt signaling is crucial in promoting neuronal cell survival and preventing apoptosis [36-40].

Sensory neurons in DRGs are known to be dependent on neurotrophic factors for their development and differentiation at embryonic and neonatal stages. In contrast, adult DRG neurons survive for several days in culture without requiring such factors. A number of signaling molecules, including PI3-K/Akt, have been suggested to be involved in age-dependent sensitivity of sensory neurons [41-45]. Adult sensory neurons may die in response to peripheral nerve injury, as shown in several in vivo studies [46-56].

Several studies have been published on localization, expression and regulation of Akt/phosphorylated Akt (pAkt) in DRG neurons and spinal cord of the rat [24-27, 57], but with regard to the mouse there are only two reports, one in vitro study [58] and one report focused on spinal motor neurons in vivo [57]. The aim of the present study is therefore to quantitatively and qualitatively investigate, in the mouse and in vivo with immunohistochemistry, p-Akt in DRG neurons and spinal cord after sciatic nerve transection and after peripheral inflammation induced by intradermal injection of carrageenan.

\section{Materials and Methods}

\section{Animals and Animal Models}

The experiments were performed on male C57BL/6J Bommince mice (A/S Bomholtgaard, Ry, Denmark) weighing 25-28 g. All animals were kept under standard conditions on a 12 -hour day/night cycle with free access to food and water. The study has been approved by the local Ethical Committee for animal experiments (Stockholms Norra Djursförsöksetiska Nämnd; N55/06). Twenty animals were anesthetized with sodium pentobarbital (Mebumal, $10 \mathrm{mg} / \mathrm{kg}$, i.p.), and the left sciatic nerve was transected at 'mid-thigh' level (axotomy; around $20 \mathrm{~mm}$ distal to the DRG). A 5-mm portion of the nerve was resected, and the proximal end was ligated to prevent regeneration. The animals were allowed to survive for 2 and 14 days after surgery $(n=10$ in each group). Twenty animals received an injection of $20 \mu \mathrm{l}$ carrageenan (1\%, Sigma, St. Louis, Mo., USA) into the plantar surface of the left hindpaw (anesthetized with sodium pentobarbital as above) and were allowed to survive for $15 \mathrm{~min}$ or $1 \mathrm{~h}$ after injection $(\mathrm{n}=$ 10 in each group).

\section{Immunohistochemistry}

All operated animals as well as control animals $(n=10)$ were deeply anesthetized with sodium pentobarbital (Mebumal; 50 $\mathrm{mg} / \mathrm{kg}$, i.p.) and transcardially perfused with $20 \mathrm{ml}$ of warm saline $\left(0.9 \% ; 37^{\circ} \mathrm{C}\right)$, followed by $20 \mathrm{ml}$ of a warm mixture of paraformaldehyde $\left(4 \% ; 37^{\circ} \mathrm{C}\right)$ with $0.4 \%$ picric acid in $0.16 \mathrm{M}$ phosphate buffer (pH 7.2) and then by $50 \mathrm{ml}$ of the same, but ice-cold fixative $[59,60]$. The L5 DRGs as well as the L4 and L5 segments of the spinal cord were dissected out and postfixed in the same fixative for $3 \mathrm{~h}$ at $4^{\circ} \mathrm{C}$ and subsequently stored in $20 \%$ sucrose in phosphate-buffered saline (PBS; pH 7.4) containing $0.01 \%$ sodium azide (Sigma) and $0.02 \%$ bacitracin (Sigma) at $4{ }^{\circ} \mathrm{C}$ for 2 days. Tissues were embedded with OCT compound (Tissue Tek, Miles Laboratories, Elkhart, Ind., USA), frozen and cut in a cryostat (Microm, Heidelberg, Germany) at 12- $\mu \mathrm{m}$ (DRGs) or 20- $\mu \mathrm{m}$ (spinal cord) thickness and mounted onto chrome-alum-gelatincoated slides. Thaw-mounted sections were dried at room temperature (RT) for $30 \mathrm{~min}$ and rinsed with PBS for $15 \mathrm{~min}$. Sections were incubated for $24 \mathrm{~h}$ at $4^{\circ} \mathrm{C}$ in a humid chamber with rabbit anti-p-Akt antiserum (1:400; Promega Neuroscience, Madison, Wisc, USA; catalogue No. G7441) diluted in PBS containing $0.2 \%$ (w/v) bovine serum albumin and $0.03 \%$ Triton X-100 (Sigma). Immunoreactivity was visualized using the tyramide signal amplification system (TSA Plus; NEN Life Science Products, Boston, Mass., USA). Briefly, the slides were rinsed with TNT buffer (0.1 M Tris-HCl, pH 7.5; $0.15 \mathrm{M} \mathrm{NaCl} ; 0.05 \%$ Tween 20) for $15 \mathrm{~min}$ at RT, blocked with TNB buffer (0.1 M Tris-HCl; pH 7.5; $0.15 \mathrm{M}$ $\mathrm{NaCl} ; 0.5 \%$ DuPont blocking reagent) for $30 \mathrm{~min}$ at RT followed by a 30 -min incubation with horseradish peroxidase-labeled swine anti-rabbit antibody (1:200; Dako, Copenhagen, Denmark) diluted in TNB buffer. After a quick wash (15 min) in TNT buffer, all sections were exposed to biotinyl tyramide-fluorescein (1:100) diluted in amplification diluent for approximately $15 \mathrm{~min}$, and finally washed in TNT buffer for $30 \mathrm{~min}$ (all steps at RT). For double-staining experiments, $\mathrm{p}$-Akt-stained sections were probed with antibodies raised against calcitonin gene-related peptide (CGRP; rabbit; 1:400) [61], galanin (rabbit; 1:400) [62] or neuropeptide Y (NPY; rabbit; 1:400) [63], visualized by lissamine rhodamine sulfonyl chloride-conjugated donkey anti-rabbit (1:100; Jackson ImmunoResearch, West Grove, Pa., USA). Another group of p-Akt-labeled sections was incubated with the isolectin B4 from Griffonia simplicifolia I (GSA I; IB4; $2.5 \mu \mathrm{g} / \mathrm{ml}$; Vector Laboratories, Burlingame, Calif., USA) followed by incubation with a goat anti-GSA I antiserum (1:4,000; Vector Laboratories) and a rhodamine red X-conjugated donkey anti-goat antibody (1:200; 

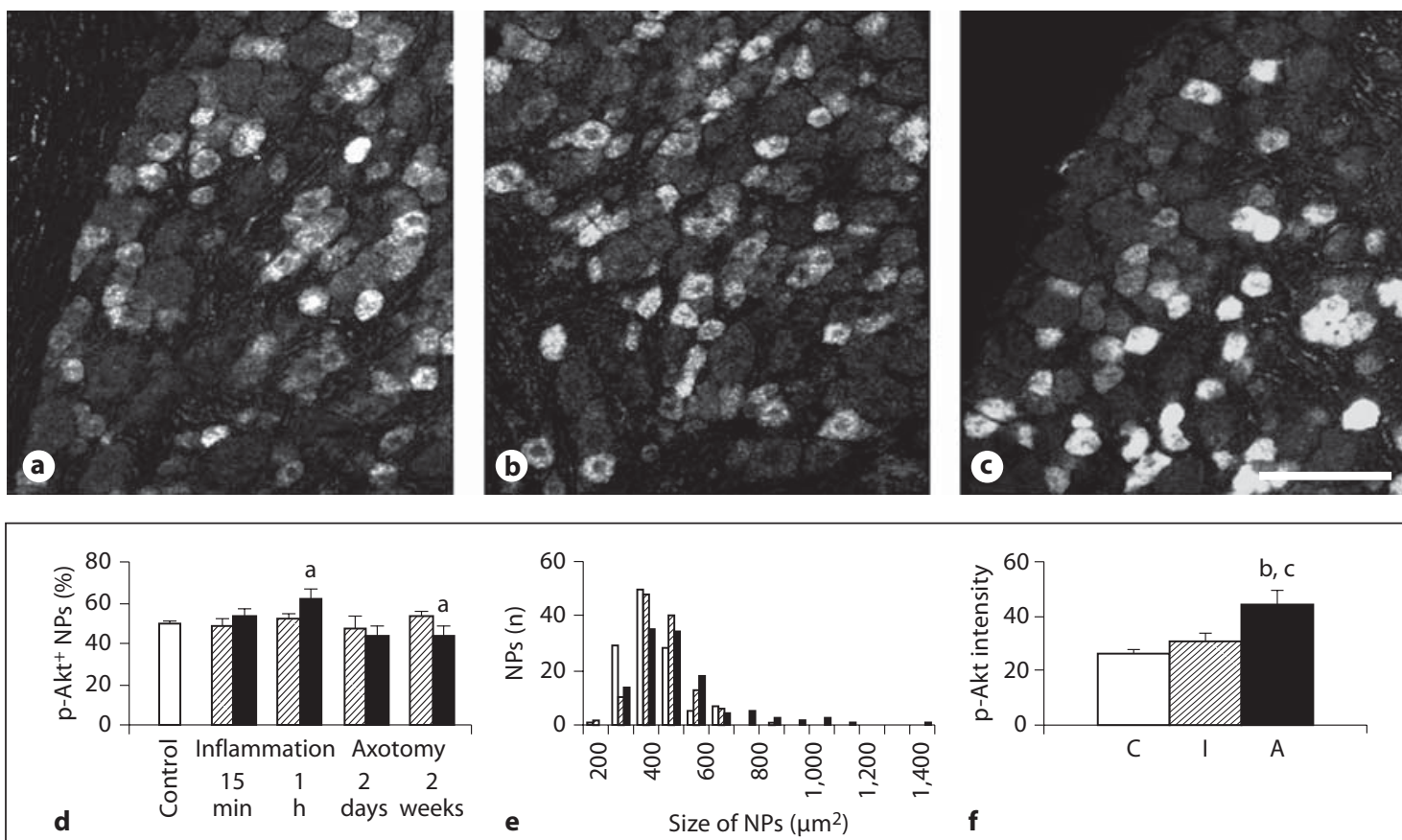

Fig. 1. Expression of p-Akt in DRGs after peripheral injury. a-c Immunofluorescence micrographs showing p-Akt-IR neurons in control animals (a), $1 \mathrm{~h}$ after carrageenan injection (b) and 14 days after axotomy (c). Of note, fluorescence intensity increased after axotomy. $\mathbf{d}$ Percentage of p-Akt-IR NPs in the DRGs of control animals $(\square)$, after inflammation, contralateral $(\square)$, or after peripheral injury, ipsilateral ( $\square$ ). e Size distribution of $\mathrm{p}$ Akt-IR NPs in control or ipsilateral DRGs after peripheral injury

Jackson ImmunoResearch). For studying the nuclear translocation of p-Akt, sections were counterstained for $15 \mathrm{~min}$ with $0.001 \%(\mathrm{w} / \mathrm{v})$ propidium iodide (PI; Sigma) in PBS. Finally, all slides were coverslipped with glycerol/PBS (9:1) containing $0.1 \%$ p-phenylenediamine $[64,65]$.

\section{Image Analysis}

Specimens were analyzed on a Bio-Rad Radiance Plus confocal scanning microscope (Bio-Rad, Hemel Hempstead, UK) installed on a Nikon Eclipse E 600 fluorescence microscope (Tokyo, Japan) equipped with $\times 10(0.5$ numerical aperture, NA), $\times 20$ $(0.75 \mathrm{NA})$ and $\times 60$ oil $(1.40 \mathrm{NA})$ objectives. Fluorescein labeling was excited using the 488-nm line of the argon ion laser and detected after passing a HQ 530/60 (Bio-Rad) emission filter. For the detection of lissamine rhodamine sulfonyl chloride and rhodamine, the 543-nm HeNe laser was used in combination with the HQ 570 (Bio-Rad) emission filter. All the slides were scanned in a series of $1-\mu \mathrm{m}$-thick optical sections. Consequently, images were analyzed separately and merged to evaluate possible colocalization. To examine the nuclear translocation of p-Akt in DRG neurons, each p-Akt-positive neuron counterstained with PI was scanned in a series of $0.5-\mu \mathrm{m}$-thick optical sections.

p-Akt in Sensory Neurons and Spinal Cord
$=$ control; $\square=$ inflammation $1 \mathrm{~h} ; \quad=$ axotomy $)(200 \mathrm{NPs}$ were measured in each group). f Immunofluorescence levels (intensity) of p-Akt-IR NPs in control (C) and ipsilateral DRGs $1 \mathrm{~h}$ after peripheral inflammation (I) or 2 weeks after axotomy (A). Error bars represent SEM. ${ }^{\mathrm{a}} \mathrm{p}<0.05$ vs. contralateral DRGs (d); ${ }^{\mathrm{b}} \mathrm{p}<0.01$ axotomy vs. control; ${ }^{\mathrm{c}} \mathrm{p}<0.01$ vs. inflammation (f). Bar indicates $100 \mu \mathrm{m}(\mathbf{a}-\mathbf{c})$.

\section{Quantitative Evaluations}

The percentage of immunoreactive (IR) neuron profiles (NPs) was counted in every fifth $12-\mu \mathrm{m}$-thick section (Nike Microphot-FX microscope, $\times 20$ objectives). The total number of $\mathrm{p}$ Akt-IR NPs was divided by the total number of PI-stained NPs (Nike Microphot-FX microscope, $\times 20$ objectives) in the DRG sections, and the percentage of positive NPs was calculated. The relative fluorescence levels (intensity) of p-Akt-like immunoreactivity (LI) in DRGs and spinal dorsal horn (lamina I-II) were measured using a Sarastro 1000 confocal laser-scanning system (Molecular Dynamics, Sunnyvale, Calif., USA). Images were recorded with a $\times 20 / 0.75$ air objective and stored in a computer for subsequent analysis in Image Space Software (Molecular Dynamics). The mean fluorescence intensity of p-Akt-LI was measured, and the ratio for whole NP versus nucleus profiles was calculated for individual p-Akt-positive neurons using the following formula:

$$
\mathrm{R}=\left[\left(\mathrm{I}_{1}-\mathrm{I}_{2}\right) /\left(\alpha_{1}-\alpha_{2}\right)\right] /\left(\mathrm{I}_{2} / \alpha_{2}\right)
$$

Here, $\mathrm{R}$ is the ratio, $\mathrm{I}_{1}$ the intensity of $\mathrm{p}$-Akt-LI in the whole NP, $\mathrm{I}_{2}$ the intensity of p-Akt-LI in the nucleus profile, $\alpha_{1}$ equals the area of the NP and $\alpha_{2}$ the area of the nucleus profile. The final ratio was the mean from 50 NPs in each group. 

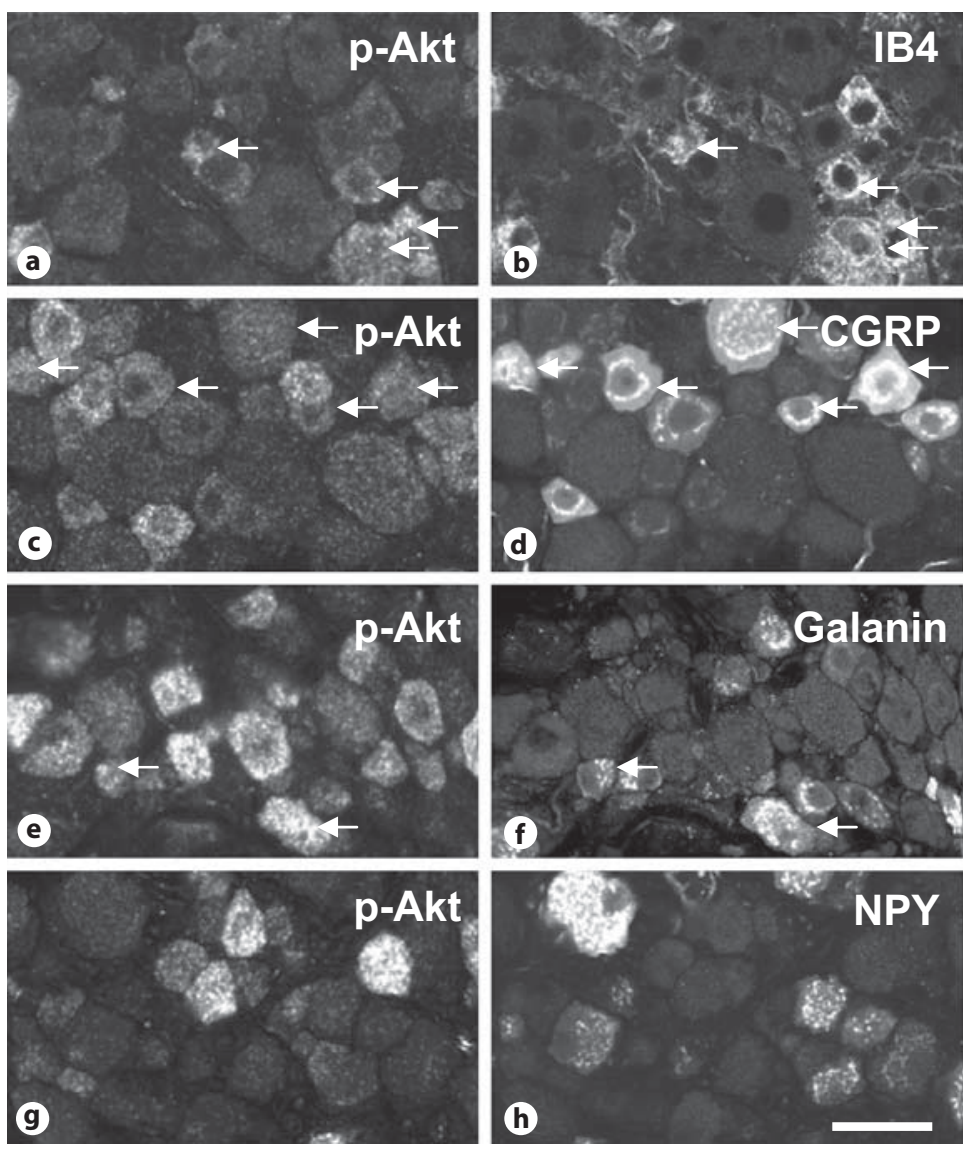

Fig. 2. Expression of p-Akt in subpopulations of DRG neurons (a-h): immunofluorescence micrographs of control (a-d) and ipsilateral DRGs 2 weeks after axotomy $(\mathbf{e}-\mathbf{h})$, incubated with antiserum to p-Akt (a, c, e, g), IB4 (b), antiserum to CGRP (d), galanin (f) or NPY (h). a/b, c/d, e/f as well as $\mathbf{g} / \mathbf{h}$ show the same sections, respectively. Arrows indicate coexistence of p-Akt with IB4 $(\mathbf{a}, \mathbf{b})$, CGRP (c, d), galanin (e, f), respectively. i-I Quantitative evalua-

The size of p-Akt-IR NPs with a visible nucleus as well as the area in the dorsal horn covered by p-Akt-IR fibers were also measured (5 animals in each group) using the Sarastro system (as above). We divided the profiles of DRG neurons into small, medium-sized and large ones according to previous studies [66, 67]. Small NPs were considered to be those with a somal area of $80-$ $600 \mu \mathrm{m}^{2}$; medium-sized 600-1,400 $\mathrm{\mu m}^{2}$, and large NPs were those with a somal area $>1,400 \mu \mathrm{m}^{2}$.

\section{Statistics}

Regarding the percentage of p-Akt-IR NPs as well as the intensity of p-Akt-LI in DRG neurons and spinal dorsal horn, differences between ipsilateral and contralateral neurons within each operated group were evaluated by Student's t test. Differences among groups were assessed using one-way ANOVA with Newman-Keuls test. A p value $<0.05$ was considered significant. tion of coexistence situations (at least 200 NPs were counted in each group). Left graphs show percentage of p-Akt-positive NPs expressing IB4 (i), CGRP (j), galanin (k) and NPY (I), respectively, and right graphs percentage of IB4- (i), CGRP- (j), galanin- (k) and NPY-positive (I) NPs expressing p-Akt, respectively. Bar indicates $50 \mu \mathrm{m}(\mathbf{a}-\mathbf{h})$.

\section{Results}

\section{p-Akt in DRGs}

In control animals, p-Akt-LI was detected in $49.5 \%$ of all DRG NPs with varying intensity levels (fig. 1a), a percentage which was not changed 2 days after axotomy (ipsilateral: $43.8 \pm 4.3 \%$ vs. contralateral: $47.2 \pm 5.3 \%$, $\mathrm{p}>0.05)$. A small but significant reduction in p-Akt-positive NPs was, however, seen in ipsilateral DRGs 2 weeks after unilateral axotomy (fig. 1d; $43.8 \pm 4.6$ vs. $52.8 \pm$ $2.7 \%, \mathrm{p}<0.05$ ), with no significant difference between control and ipsilateral DRGs (fig. $1 \mathrm{~d} ; 49.5 \pm 1.5$ vs. 43.8 $\pm 4.6 \%, \mathrm{p}>0.05)$. The proportion of $\mathrm{p}$-Akt-IR NPs was similar between ipsi- and contralateral DRGs (53.2 \pm 4.2 
vs. $48.8 \pm 3.0 \%, p>0.05) 15$ min after unilateral intraplantar injection of carrageenan. However, p-Akt levels were significantly increased $1 \mathrm{~h}$ after injection (fig. 1d; $62.0 \pm 4.4$ vs. $51.8 \pm 2.3 \%$, ipsi- vs. contralateral, respectively; $\mathrm{p}<0.05)$. The percentage of $\mathrm{p}$-Akt-IR NPs in contralateral DRGs in each lesion group was similar to control (fig. 1d; $\mathrm{p}>0.05$ ). Most $\mathrm{p}$-Akt-IR NPs were smallsized NPs $\left(<600 \mu \mathrm{m}^{2}\right)$, but 2 weeks after nerve injury there seemed to be more medium-sized neurons expressing p-Akt in the ipsilateral DRGs than in controls (fig. 1e). The intensity of p-Akt-LI in individual neurons increased significantly in 2-week-axotomized DRGs as compared to control and to 1-hour inflamed DRGs, respectively (fig. 1 ; $44.6 \pm 4.7$ vs. $26.5 \pm 1.3$ or $31.0 \pm 3.1$; $p<0.01$; cf. fig. 1c with a, b). In control DRGs, many p-Akt-positive neurons were IB4-IR (fig. 2a, b); about half of the $\mathrm{p}$ Akt-IR NPs coexpressed IB4, and 83\% of the IB4-IR NPs were p-Akt positive (fig. $2 \mathrm{i}$ ). In addition, $53 \%$ of the pAkt-positive NPs stained for CGRP-LI, and $57 \%$ of the CGRP-IR NPs also expressed p-Akt (fig. 2c, d, j). Two weeks after axotomy, around one third of the p-Akt-positive NPs expressed galanin, a peptide which is strongly upregulated after nerve injury [2], mainly in small and medium-sized DRG NPs (fig. 2e, f, k). Almost no p-AktIR NPs coexpressed NPY, a peptide dramatically increased in large-sized DRG NPs after nerve injury [68] (fig. 2g, h, l).

\section{Subcellular Translocation of p-Akt in DRGs}

In control animals, p-Akt-LI (green) was mostly present in the cytoplasm of DRG neurons, with only weak staining in the nucleus (fig. 3a). Two weeks after axotomy, the strong upregulation of p-Akt was associated with higher levels in both the cytoplasm (fig. 1c, f; fig. 3b) and the nucleus (fig. 3b). The labeling ratio for whole NP versus nuclear profiles was $0.07 \pm 0.03$ in controls and decreased to $-0.02 \pm 0.02$ and $-0.11 \pm 0.01$ in the 1-hour 'inflamed' and 2-week-axotomized DRGs, respectively (fig. 3c). The increased nuclear translocation of active Akt was further demonstrated in serial, optical slices through the nucleus of a single neuron of control (fig. 3d, top) and 2-week-axotomized (fig. 3d, bottom) animals.

\section{p-Akt in Spinal Cord}

p-Akt-LI was found in a dense fiber plexus in dorsal horn laminae I and II of control animals (fig. 3e, f), but p-Akt-positive cell bodies could not be detected. In addition, a few but weakly labeled p-Akt-IR motor neurons were observed in the ventral horns (fig. 3g). A 2-week axotomy caused expansion of p-Akt-IR fibers into the deeper layers (from laminae I-II to III-IV or even V; fig. $3 \mathrm{e}, \mathrm{h} ; 49.4 \pm 4.6$ vs. $33.8 \pm 2.1, \mathrm{p}<0.01$ vs. contralateral) with a parallel increase in labeling intensity (fig. $3 \mathrm{~h}$; $25.8 \pm 5.7$ vs. $13 \pm 1.9, p<0.05$ vs. control). However, no effect was seen ipsilaterally after inflammation (fig. $3 \mathrm{~h}$; $36.4 \pm 2.3$ vs. $37 \pm 3.0$ in the 15 -min group, $p>0.05 ; 36$ \pm 2.0 vs. $38.3 \pm 2.4$ in the 1-hour group, $p>0.05$ ). p-Akt levels did not differ between ipsi- and contralateral sides, neither after inflammation nor axotomy (inflammation 15 min: $9.8 \pm 3.1$ vs. $14 \pm 1.6, p>0.05$; inflammation 1 h: $18.7 \pm 2.2$ vs. $16.7 \pm 1.5, \mathrm{p}>0.05$; axotomy 2 days: $13.4 \pm 2.5$ vs. $10.4 \pm 2.1, \mathrm{p}>0.05$ ).

Double-labeling experiments showed that a 2 -week unilateral axotomy reduces ipsilateral CGRP-IR fibers (red; fig. $4 \mathrm{a} / \mathrm{b}$ ), in contrast to the marked increase and expansion of p-Akt-IR fibers (green; fig. $4 \mathrm{~b} / \mathrm{a}, \mathrm{d} / \mathrm{c}, \mathrm{f} / \mathrm{e}$ ) from laminae I-II to III-IV. Galanin-IR fibers increased in laminae I-II and also in lamina III (red; fig. 4c/d). NPY-IR fibers were also increased in laminae I-II and more so in laminae III-IV (red; fig. 4e/f). Partial overlap (yellow) of p-Akt-LI (green, fig. 4a-f) with CGRP- (red; fig. 4a, b), galanin- (red; fig. 4c, d) or NPY-LIs (red; fig. 4e, f) was observed contra- (fig. 4a, c, e) and ipsilaterally (fig. $4 \mathrm{~b}, \mathrm{~d}, \mathrm{f}$ ). Note that the separation of colors/markers is most distinct for p-Akt versus CGRP, due to the fact that CGRP is downregulated after axotomy, whereas pAkt is both upregulated and expands into deeper layers. Using the confocal microscope, it was possible to analyze, at least to some degree, actual coexistence (yellow; fig. 4go), whereby p-Akt mostly colocalized with CGRP (fig. 4gi), less so with galanin (fig. $4 \mathrm{j}-\mathrm{l}$ ) and to a very limited extent with NPY (fig. $4 \mathrm{~m}-\mathrm{o}$ ).

\section{Discussion}

The present in vivo study in the adult mouse demonstrates that under normal conditions Akt is phosphorylated in around 50\% (mostly small sized) of all DRG neurons, both 'non-peptidergic' ( $\sim 50 \%$ are IB4-positive) and peptidergic ( $\sim 53 \%$ are CGRP-positive) populations. Peripheral axotomy caused a marked increase in p-Akt levels, whereas inflammation significantly increased the percentage of p-Akt-IR NPs without affecting phosphorylated protein levels. Moreover, both axotomy and inflammation caused translocation of p-Akt into nuclei. In the spinal dorsal horn, the ipsilateral p-Akt-IR fibers increased and expanded into deeper layers after unilateral axotomy, but such an effect was not seen after inflammation. 

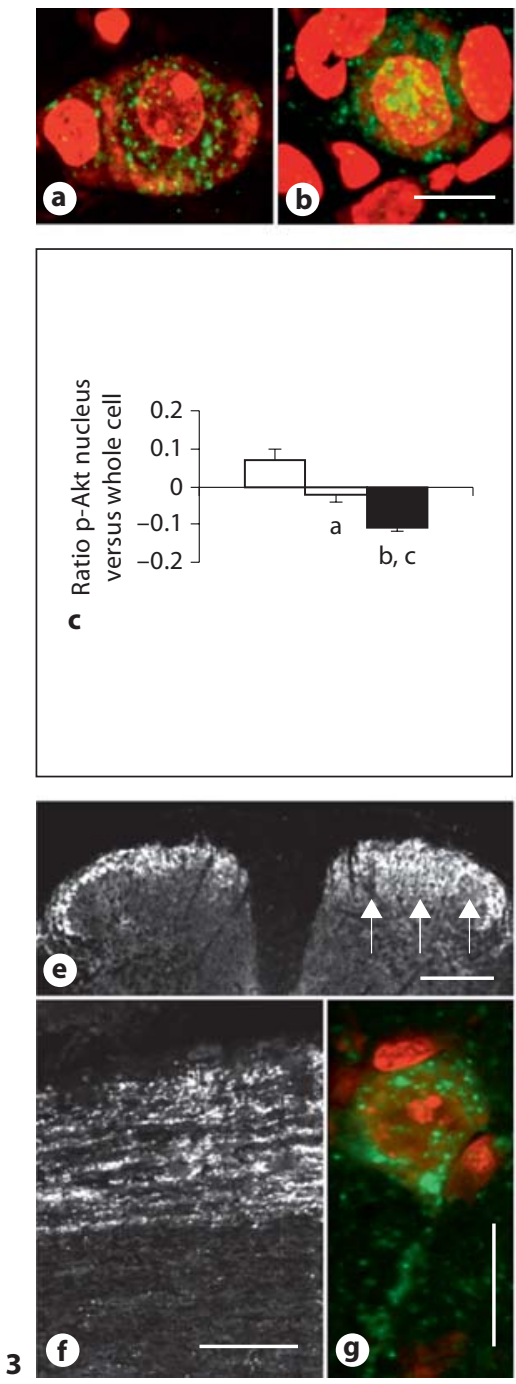

3 f

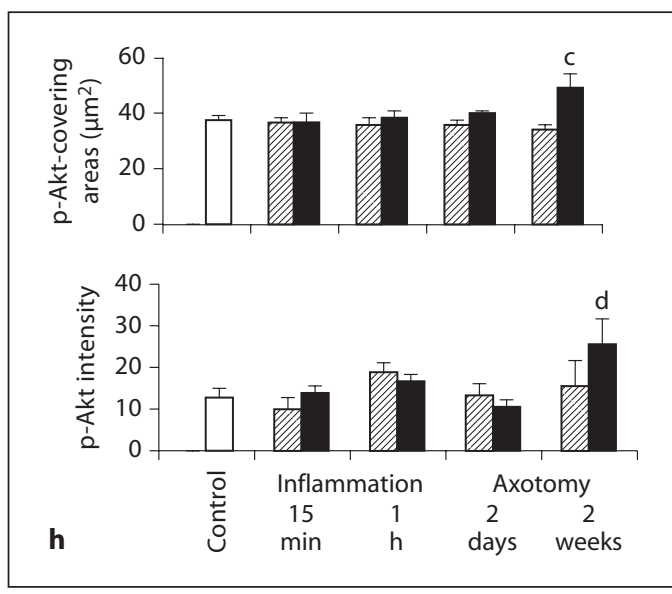

(d)
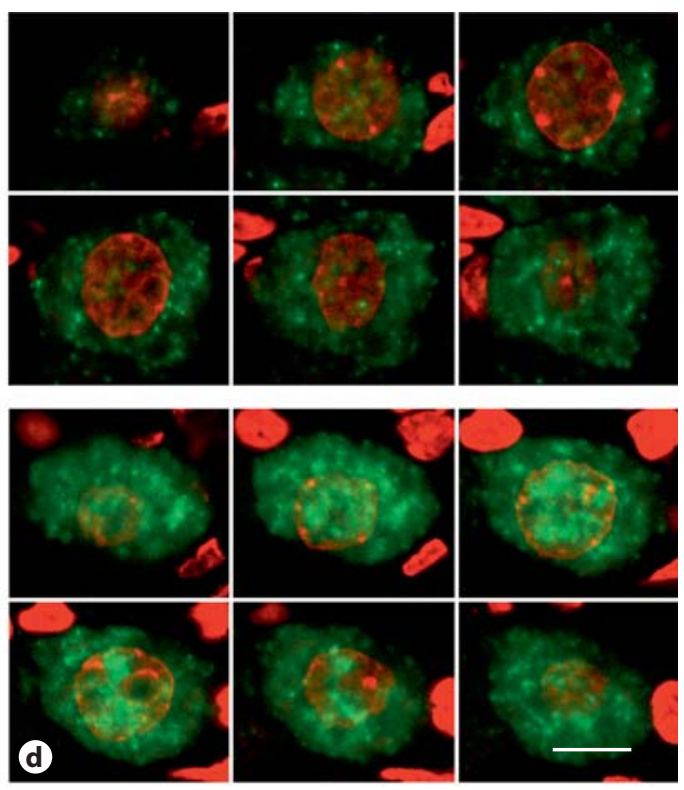
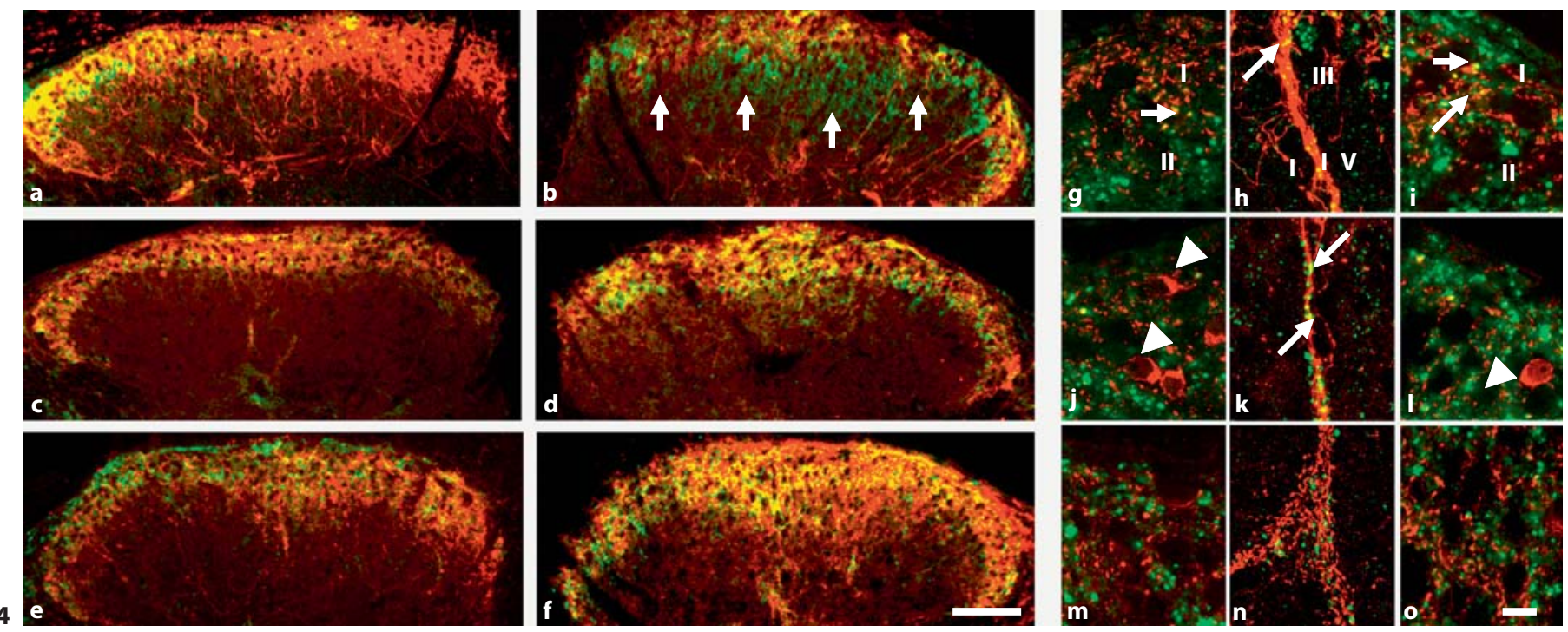
Pezet et al. [25] reported that very low p-Akt levels were present in 'almost all neurons' in the rat. This is in agreement with the in vitro study in the mouse by Edström and Ekström [58], reporting that most neurons from freshly dissected DRGs are p-Akt-IR, whereas other cell types, such as satellite cells, were negative. Zhuang et al. [24] and $\mathrm{Xu}$ et al. [26] found that $\sim 10 \%$ of rat DRG neurons are $\mathrm{p}$ Akt positive, versus our $50 \%$ in the mouse. This could represent a species difference but could also be due to our use of the sensitive TSA immunohistochemical method.

Fig. 3. Nuclear expression of p-Akt in DRG neurons. a, b Confocal micrographs showing staining with p-Akt antiserum (green) and PI (red) to visualize the nucleus in control (a) and ipsilateral (b) DRG 2 weeks after axotomy. Of note, nuclear translocation of p-Akt-LI increased after axotomy compared with control. c Confocal images were collected and quantified, and the ratio of nuclear fluorescence versus whole cell fluorescence was calculated (50 NPs were counted in each group). First column = Control; second column $=$ inflammation $1 \mathrm{~h}$; third column $=$ axotomy 2 weeks. Error bars represent SEM. ${ }^{a} \mathrm{p}<0.01,{ }^{\mathrm{b}} \mathrm{p}<0.001$ vs. control, ${ }^{\mathrm{c}} \mathrm{p}<0.01$ vs. DRG treated by carrageenan. $\mathbf{d}$ Confocal images were collected from two individual neurons in control (top) or 2-week-axotomized (bottom) DRG. e-g Expression of p-Akt in spinal cord. e Immunofluorescence micrograph of p-Akt-IR in lumbar spinal cord 2 weeks after axotomy. p-Akt-IR fibers, mainly located in laminae I and II in control, extend to the deeper laminae after unilateral nerve injury (arrows). No clear p-Akt-IR cell body can be seen in the dorsal horns. $f$ Expression of p-Akt-LI in the contralateral superficial spinal dorsal horn (longitudinal section). $\mathbf{g}$ Expression of p-Akt-LI (green) in a motor neuron in lumbar spinal ventral horn in a control animal shown after double-labeling with PI (red, confocal). h Quantitative evaluation of p-Akt-LI in the spinal dorsal horn indicates that a 2-week-axotomy causes a significant increase in area covered by p-Akt-LI ( ${ }^{c} \mathrm{p}<0.01$ vs. control or contralateral). A significant increase in p-Akt-IR levels (intensity) is found in the ipsilateral dorsal horn 14 days after axotomy ( ${ }^{\mathrm{d}} \mathrm{p}<0.05$ vs. control). Bars indicate 10 (a, b, d), $100(\mathbf{e}, \mathbf{f})$ and $50 \mu \mathrm{m}(\mathbf{g})$

Fig. 4. p-Akt is coexpressed with neuropeptides in the spinal cord. a-f Immunofluorescence micrographs of contra- (a, c, e) and ipsilateral (b, d, f) dorsal horns 2 weeks after axotomy and double staining with antiserum against p-Akt (a-f; green), CGRP (a, b; red), galanin (c, d; red) or NPY (e, f; red). Note that p-Akt expansion into deeper layers is most distinctly seen in $\mathbf{b}$ (arrows), since CGRP-LI in fibers has been reduced as a consequence of the axotomy. g-o Confocal immunofluorescence micrographs of contra$(\mathbf{g}, \mathbf{h}, \mathbf{j}, \mathbf{k}, \mathbf{m}, \mathbf{n})$ and ipsilateral $(\mathbf{i}, \mathbf{l}, \mathbf{o})$ dorsal horns 2 weeks after axotomy, coincubated with p-Akt antiserum (g-o, green) and CGRP ( $\mathbf{g}, \mathbf{h}, \mathbf{I}$, red), galanin (j, $\mathbf{k}, \mathbf{l}$, red) or NPY antiserum $(\mathbf{m}, \mathbf{n}$, $\mathbf{o}$, red), respectively. $\mathbf{g}, \mathbf{i}, \mathbf{j}, \mathbf{I}, \mathbf{m}, \mathbf{o}$ Mid part of superficial layers (I-II). h, k, n Mid part of deep layers (III-V). Note that colocalization is most frequent for CGRP ( $\mathbf{g}-\mathbf{i}$, arrows), less so for galanin ( $\mathbf{k}$, arrows; $\mathbf{j}, \mathbf{I}$ : arrowheads indicate galanin-IR interneurons in the superficial dorsal horn) and very limited for NPY. Bars indicate $100(\mathbf{a}-\mathbf{f})$ and $50 \mu \mathrm{m}(\mathbf{g}-\mathbf{o})$.

p-Akt in Sensory Neurons and Spinal Cord
Similar to the rat $[25,26]$, in the mouse many p-Akt-IR neurons stain for IB4, a marker for small, non-peptidergic neurons [69-72]. With regard to the peptide phenotype, $30-50 \%$ of the p-Akt-positive NPs express CGRP both in rats [25] and mice (present results). Thus, p-Akt neurons are both peptidergic and non-peptidergic neurons in both species.

Activation of Akt in rat DRGs has been shown after intradermal injection of capsaicin [24]. In agreement, Pezet et al. [25] reported a rapid onset and time-dependent upregulation of p-Akt in small and medium-sized DRG neurons after peripheral administration of capsaicin, which was reduced by blocking neuronal activity in the sciatic nerve using tetrodotoxin. However, we only saw a very limited effect of intradermal carrageenan, which, like capsaicin, is associated with inflammatory mechanisms.

The report by $\mathrm{Xu}$ et al. [26], the only study, to our knowledge, of p-Akt after peripheral nerve injury (L5 spinal nerve ligation), showed an early, transient upregulation of p-Akt in rat DRGs, predominantly in IB4-positive neurons, followed by a strong reduction 7 days after nerve injury, apparently contrasting our lack of effect at 2 days and strong upregulation 2 weeks after axotomy. Our findings also seem to contrast the marked decrease in pAkt after $24 \mathrm{~h}$ in mouse DRG cultures, where all neurons, of course, have been axotomized, an effect which, however, was recorded very early, just after $24 \mathrm{~h}$ in culture [58]. So the differences could be explained by different experimental models and/or species differences.

We compared p-Akt with some neuropeptides known to be upregulated after peripheral nerve injury in the mouse $[67,73]$. Thus, p-Akt was expressed in some galanin-, but rarely in NPY-positive neurons, in agreement with the fact that in the mouse galanin is mainly upregulated in small/medium-sized neurons and NPY mainly in large neurons.

In the rat spinal cord, $\mathrm{p}$-Akt-LI has been described in both dorsal (fibers and interneurons) $[26,27]$ and ventral (motor neurons) [57] horns, only in partial agreement with our findings, since we did not see p-Akt in local dorsal horn neurons, not even after carrageenan or axotomy. Sun et al. [27] reported that capsaicin injection leads to upregulation of p-Akt in rat interneurons in the ipsilateral dorsal horn, and Murashov et al. [57] detected increased p-Akt levels in mouse motor neurons after sciatic nerve transection. We could not confirm any of these two findings.

In addition to the ipsilateral expansion into deeper layers after axotomy in the mouse, we also observed in-

Neurosignals 2009;17:203-212 
creased levels of p-Akt after nerve injury, as also indicated by previous studies in the rat $[26,27]$. In fact, our studies indicate that virtually all p-Akt-LI in the dorsal horn originates in DRGs. The expansion of p-Akt to deeper layers in the dorsal horn is in agreement with our findings that p-Akt expression after axotomy occurs also in larger neurons than the normally p-Akt-positive ones, i.e. a shift towards mid-sized DRG neurons. However, it is unclear exactly what class of DRG neurons is involved. It does not seem to be the NPY-positive population, which also projects to deeper layers, both in the rat [68] and mouse $[67,73]$.

Studies on cultured embryonic DRG neurons show that growth factor-related survival is associated with nuclear accumulation of p-Akt [74]. In the present study, we found a significantly increased nuclear presence of $\mathrm{p}$-Akt in DRG neurons after peripheral injury in vivo. While the functional significance of cytoplasmic PI3-K/Akt is well established [75-80], less is known about its role in the nucleus. Nuclear Akt has been reported to exert an antiapoptotic function via phosphorylation of acinus, a nuclear factor required for chromatin condensation [81]. Akt phosphorylates acinus and inhibits its proteolytic cleavage, preventing chromatin condensation. Upregulation of nuclear p-Akt may be an additional protective mechanism used by cells for escaping death induced by cellular stress.
Taken together, the present study shows that localization, expression and regulation of p-Akt in the mouse are often similar to previous reports in the rat $[24-27,57]$. However, distinct differences may exist, but the use of different experimental models and immunohistochemical techniques make a direct comparison difficult. Most studies indicate that all p-Akt in the dorsal horn originates in DRGs. The expansion of p-Akt to deeper layers in the dorsal horn after peripheral manipulations is in agreement with the findings that $\mathrm{p}$-Akt expression after axotomy occurs in larger neurons than those normally expressing in $\mathrm{p}$-Akt, but not in the population of large NPY-positive neurons.

\section{Acknowledgments}

This study was supported by the Swedish Research Council (04X-2887, 62X-10815), the Marianne and Marcus Wallenberg Foundation, the Knut and Alice Wallenberg Foundation and the Swedish Brain Foundation. We are grateful to Prof. Peter Wallin for allowing us to use their confocal microscope for image analysis, and to Prof. Lars Terenius, Center for Molecular Medicine, Karolinska Institutet, Stockholm (CGRP), and Prof. Elvar Theodorsson, Department of Clinical and Experimental Medicine, University Hospital, Linköping (galanin), for generous supply of antisera.

\section{References}

1 Willis WDJ, Coggeshall RE: Sensory Mechanisms of the Spinal Cord. New York, Plenum, 2004.

2 Hökfelt T, Zhang X, Wiesenfeld-Hallin Z: Messenger plasticity in primary sensory neurons following axotomy and its functional implications. Trends Neurosci 1994;17: 22-30.

3 Hökfelt T, Zhang X, Xu X, Wiesenfeld-Hallin $Z$ : Central consequences of peripheral nerve damage; in McMahon SB, Koltzenburg M (eds): Textbook of Pain. Amsterdam, Elsevier, 2006, pp 947-959.

4 Zigmond RE, Hyatt-Sachs H, Mohney RP, Schreiber RC, Shadiack AM, Sun Y, Vaccariello SA: Changes in neuropeptide phenotype after axotomy of adult peripheral neurons and the role of leukemia inhibitory factor. Perspect Dev Neurobiol 1996;4:75-90.

5 Basbaum AI: Distinct neurochemical features of acute and persistent pain. Proc Nat Acad Sci USA 1999;96:7739-7743.

6 Zimmermann M: Pathobiology of neuropathic pain. Eur J Pharmacol 2001;429:2337.
7 Wang H, Sun H, Della Penna K, et al: Chronic neuropathic pain is accompanied by global changes in gene expression and shares pathobiology with neurodegenerative diseases. Neuroscience 2002;114:529-546.

8 Costigan M, Befort K, Karchewski L, Griffin RS, D'Urso D, Allchorne A, Sitarski J, Mannion JW, Pratt RE, Woolf CJ: Replicate highdensity rat genome oligonucleotide microarrays reveal hundreds of regulated genes in the dorsal root ganglion after peripheral nerve injury. BMC Neurosci 2002;3:16.

$\checkmark 9$ Xiao HS, Huang QH, Zhang FX, Bao L, Lu YJ, Guo C, Yang L, Huang WJ, Fu G, Xu SH, Cheng XP, Yan Q, Zhu ZD, Zhang X, Chen Z, Han ZG, Zhang X: Identification of gene expression profile of dorsal root ganglion in the rat peripheral axotomy model of neuropathic pain. Proc Natl Acad Sci USA 2002; 99:8360-8365.

10 Franke TF, Kaplan DR, Cantley LC, Toker A: Direct regulation of the Akt proto-oncogene product by phosphatidylinositol-3,4-bisphosphate. Science 1997;275:665-668.
11 Chan TO, Rittenhouse SE, Tsichlis PN: AKT/ $\mathrm{PKB}$ and other D3 phosphoinositide-regulated kinases: kinase activation by phosphoinositide-dependent phosphorylation. Annu Rev Biochem 1999;68:965-1014.

12 Ashcroft M, Stephens RM, Hallberg B, Downward J, Kaplan DR: The selective and inducible activation of endogenous PI 3-kinase in PC12 cells results in efficient NGFmediated survival but defective neurite outgrowth. Oncogene 1999;18:4586-4597.

-13 Barber AJ, Nakamura M, Wolpert EB, Reiter CE, Seigel GM, Antonetti DA, Gardner TW: Insulin rescues retinal neurons from apoptosis by a phosphatidylinositol 3-kinase/Aktmediated mechanism that reduces the activation of caspase-3. J Biol Chem 2001;276: 32814-32821.

14 Brunet A, Datta SR, Greenberg ME: Transcription-dependent and -independent control of neuronal survival by the PI3K-Akt signaling pathway. Curr Opin Neurobiol 2001;11:297-305. 
-15 Dudek H, Datta SR, Franke TF, Birnbaum MJ, Yao R, Cooper GM, Segal RA, Kaplan DR, Greenberg ME: Regulation of neuronal survival by the serine-threonine protein kinase Akt. Science 1997;275:661-665.

-16 Dolcet X, Egea J, Soler RM, Martin-Zanca D, Comella JX: Activation of phosphatidylinositol 3-kinase, but not extracellular-regulated kinases, is necessary to mediate brainderived neurotrophic factor-induced motoneuron survival. J Neurochem 1999;73:521531.

-17 Rodgers EE, Theibert AB: Functions of PI 3kinase in development of the nervous system. Int J Dev Neurosci 2002;20:187-197.

-18 Hou L, Klann E: Activation of the phosphoinositide 3-kinase-Akt-mammalian target of rapamycin signaling pathway is required for metabotropic glutamate receptor-dependent long-term depression. J Neurosci 2004;24:6352-6361.

-19 Ciani E, Virgili M, Contestabile A: Akt pathway mediates a cGMP-dependent survival role of nitric oxide in cerebellar granule neurones. J Neurochem 2002;81:218-228.

$\checkmark 20$ Kelly A, Lynch MA: Long-term potentiation in dentate gyrus of the rat is inhibited by the phosphoinositide 3-kinase inhibitor, wortmannin. Neuropharmacology 2000;39:643651.

-21 Lin CH, Lee CC, Gean PW: Involvement of a calcineurin cascade in amygdala depotentiation and quenching of fear memory. Mol Pharmacol 2003;63:44-52.

-22 Wang Q, Liu L, Pei L, Ju W, Ahmadian G, Lu J, Wang Y, Liu F, Wang YT: Control of synaptic strength, a novel function of Akt. Neuron 2003;38:915-928.

-23 Ivanova T, Mendez P, Garcia-Segura LM, Beyer C: Rapid stimulation of the PI3-kinase/Akt signalling pathway in developing midbrain neurones by oestrogen. J Neuroendocrinol 2002;14:73-79.

-24 Zhuang ZY, Xu H, Clapham DE, Ji RR: Phosphatidylinositol 3-kinase activates ERK in primary sensory neurons and mediates inflammatory heat hyperalgesia through TRPV1 sensitization. J Neurosci 2004;24: 8300-8309.

-25 Pezet S, Spyropoulos A, Williams RJ, McMahon SB: Activity-dependent phosphorylation of Akt/PKB in adult DRG neurons. Eur J Neurosci 2005;21:1785-1797.

-26 Xu JT, Tu HY, Xin WJ, Liu XG, Zhang GH, Zhai CH: Activation of phosphatidylinositol 3-kinase and protein kinase B/Akt in dorsal root ganglia and spinal cord contributes to the neuropathic pain induced by spinal nerve ligation in rats. Exp Neurol 2007;206:269279.

-27 Sun RQ, Tu YJ, Yan JY, Willis WD: Activation of protein kinase B/Akt signaling pathway contributes to mechanical hypersensitivity induced by capsaicin. Pain 2006;120: 86-96.
28 Lewin GR, Barde YA: Physiology of the neurotrophins. Annu Rev Neurosci 1996;19. 289-317.

29 Lindsay RM: Role of neurotrophins and trk receptors in the development and maintenance of sensory neurons: an overview. Philos Trans R Soc Lond B Biol Sci 1996;351 365-373.

30 Huang EJ, Reichardt LF: Trk receptors: roles in neuronal signal transduction. Annu Rev Biochem 2003;72:609-642.

31 Goldberg JL, Barres BA: The relationship between neuronal survival and regeneration. Annu Rev Neurosci 2000;23:579-612.

32 Pang L, Sawada T, Decker SJ, Saltiel AR: Inhibition of MAP kinase kinase blocks the differentiation of PC-12 cells induced by nerve growth factor. J Biol Chem 1995;270: 13585-13588.

33 Vetter ML, Martin-Zanca D, Parada LF, Bishop JM, Kaplan DR: Nerve growth factor rapidly stimulates tyrosine phosphorylation of phospholipase C-gamma 1 by a kinase activity associated with the product of the trk protooncogene. Proc Natl Acad Sci USA 1991;88:5650-5654.

34 Grewal SS, York RD, Stork PJ: Extracellularsignal-regulated kinase signalling in neurons. Curr Opin Neurobiol 1999;9:544-553.

35 Meyer GE, Shelden E, Kim B, Feldman EL: Insulin-like growth factor I stimulates motility in human neuroblastoma cells. Oncogene 2001;20:7542-7550.

36 Yao R, Cooper GM: Regulation of the Ras signaling pathway by GTPase-activating protein in PC12 cells. Oncogene 1995;11: 1607-1614.

37 Crowder RJ, Freeman RS: Phosphatidylinositol 3-kinase and Akt protein kinase are necessary and sufficient for the survival of nerve growth factor-dependent sympathetic neurons. J Neurosci 1998;18:2933-2943.

-38 Datta SR, Brunet A, Greenberg ME: Cellular survival: a play in three Akts. Genes Dev 1999;13:2905-2927.

39 Yuan J, Yankner BA: Apoptosis in the nervous system. Nature 2000;407:802-809.

40 Orike N, Middleton G, Borthwick E, Buchman V, Cowen T, Davies AM: Role of PI 3 kinase, Akt and Bcl-2-related proteins in sustaining the survival of neurotrophic factor-independent adult sympathetic neurons. J Cell Biol 2001;154:995-1005.

41 Memberg SP, Hall AK: Proliferation, differentiation, and survival of rat sensory neuron precursors in vitro require specific trophic factors. Mol Cell Neurosci 1995;6:323-335.

42 Molliver DC, Snider WD: Nerve growth factor receptor TrkA is down-regulated during postnatal development by a subset of dorsal root ganglion neurons. J Comp Neurol 1997; 381:428-438.

43 Vogelbaum MA, Tong JX, Rich KM: Developmental regulation of apoptosis in dorsal root ganglion neurons. J Neurosci 1998; 18 : 8928-8935.
44 White FA, Silos-Santiago I, Molliver DC, Nishimura M, Phillips H, Barbacid M, Snider WD: Synchronous onset of NGF and TrkA survival dependence in developing dorsal root ganglia. J Neurosci 1996;16:4662-4672.

45 Salvarezza SB, Lopez HS, Masco DH: The same cellular signaling pathways mediate survival in sensory neurons that switch their trophic requirements during development. J Neurochem 2003;85:1347-1358.

$\checkmark 46$ Carlson J, Lais AC, Dyck PJ: Axonal atrophy from permanent peripheral axotomy in adult cat. J Neuropathol Exp Neurol 1979;38:579585.

47 Risling M, Aldskogius H, Hildebrand C, Remahl S: Effects of sciatic nerve resection on L7 spinal roots and dorsal root ganglia in adult cats. Exp Neurol 1983;82:568-580.

-48 Devor M, Govrin-Lippmann R, Frank I, Raber P: Proliferation of primary sensory neurons in adult rat dorsal root ganglion and the kinetics of retrograde cell loss after sciatic nerve section. Somatosens Res 1985;3:139-167.

49 Tessler A, Himes BT, Krieger NR, Murray M, Goldberger ME: Sciatic nerve transection produces death of dorsal root ganglion cells and reversible loss of substance $\mathrm{P}$ in spinal cord. Brain Res 1985;332:209-218.

50 Arvidsson J, Ygge J, Grant G: Cell loss in lumbar dorsal root ganglia and transganglionic degeneration after sciatic nerve resection in the rat. Brain Res 1986;373:15-21.

51 Himes BT, Tessler A: Death of some dorsal root ganglion neurons and plasticity of others following sciatic nerve section in adult and neonatal rats. J Comp Neurol 1989;284: 215-230.

52 Tandrup T: A method for unbiased and efficient estimation of number and mean volume of specified neuron subtypes in rat dorsal root ganglion. J Comp Neurol 1993;329: 269-276.

53 Vestergaard S, Tandrup T, Jakobsen J: Effect of permanent axotomy on number and volume of dorsal root ganglion cell bodies. J Comp Neurol 1997;388:307-312.

54 Shi TJ, Tandrup T, Bergman E, Xu ZQ, Ulfhake B, Hökfelt T: Effect of peripheral nerve injury on dorsal root ganglion neurons in the C57 BL/6J mouse: marked changes both in cell numbers and neuropeptide expression. Neuroscience 2001;105:249-263.

55 Shi TJ, Hua XY, Lu X, Malkmus S, Kinney J, Holmberg K, Wirz S, Ceccatelli S, Yaksh T, Bartfai T, Hökfelt T: Sensory neuronal phenotype in galanin receptor 2 knockout mice: focus on dorsal root ganglion neurone development and pain behaviour. Eur J Neurosci 2006;23:627-636

56 Shi TJ, Li J, Dahlström A, Theodorsson E, Ceccatelli S, Decosterd I, Pedrazzini T, Hökfelt T: Deletion of the neuropeptide Y Y1 receptor affects pain sensitivity, neuropeptide transport and expression, and dorsal root ganglion neuron numbers. Neuroscience 2006;140:293-304. 
57 Murashov AK, Ul Haq I, Hill C, Park E, Smith M, Wang X, Wang X, Goldberg DJ, Wolgemuth DJ: Crosstalk between p38, Hsp25 and Akt in spinal motor neurons after sciatic nerve injury. Brain Res Mol Brain Res 2001;93:199-208.

- 58 Edström A, Ekström PA: Role of phosphatidylinositol 3-kinase in neuronal survival and axonal outgrowth of adult mouse dorsal root ganglia explants. J Neurosci Res 2003; 74:726-735.

59 Pease P: Buffered formaldehyde as a killing agent and primary fixative for electron microscopy. Anat Rec 1962;142:342.

-60 Zamboni I, De Martino C: Buffered picric acid formaldehyde. A new rapid fixative for electron microscopy. J Cell Biol 1967;35: $148 \mathrm{~A}$.

-61 Orazzo C, Pieribone VA, Ceccatelli S, Terenius L, Hökfelt T: CGRP-like immunoreactivity in A11 dopamine neurons projecting to the spinal cord and a note on CGRP-CCK cross-reactivity. Brain Res 1993;600:39-48.

62 Theodorsson E, Rugarn O: Radioimmunoassay for rat galanin: immunochemical and chromatographic characterization of immunoreactivity in tissue extracts. Scand J Clin Lab Invest 2000;60:411-418.

-63 Brumovsky P, Stanic D, Shuster S, Herzog H, Villar M, Hökfelt T: Neuropeptide Y2 receptor protein is present in peptidergic and nonpeptidergic primary sensory neurons of the mouse. J Comp Neurol 2005;489:328-348.

64 Johnson GD, Nogueira Araujo GM: A simple method of reducing the fading of immunofluorescence during microscopy. J Immunol Methods 1981;43:349-350.

- 65 Platt JL, Michael AF: Retardation of fading and enhancement of intensity of immunofluorescence by $p$-phenylenediamine. J Histochem Cytochem 1983;31:840-842.
66 Dubovy P, Svizenska I, Vega JA: Non-specific cholinesterase activity in mouse spinal ganglia. The usefulness of histochemical study and image analysis for simple characterization of neuron subclasses. Cell $\mathrm{Mol}$ Biol 1990;36:23-40.

67 Shi TJ, Zhang X, Berge OG, Erickson JC, Palmiter RD, Hökfelt T: Effect of peripheral axotomy on dorsal root ganglion neuron phenotype and autonomy behaviour in neuropeptide Y-deficient mice. Regul Pept 1998; 75-76:161-173.

68 Wakisaka S, Kajander KC, Bennett GJ: Increased neuropeptide Y (NPY)-like immunoreactivity in rat sensory neurons following peripheral axotomy. Neurosci Lett 1991; 124:200-203.

69 Kashiba H, Uchida Y, Senba E: Difference in binding by isolectin B4 to trkA and c-ret mRNA-expressing neurons in rat sensory ganglia. Brain Res Mol Brain Res 2001;95: $18-26$.

-70 Wang H, Rivero-Melian C, Robertson B, Grant G: Transganglionic transport and binding of the isolectin B4 from Griffonia simplicifolia I in rat primary sensory neurons. Neuroscience 1994;62:539-551.

71 Zwick M, Davis BM, Woodbury CJ, Burkett JN, Koerber HR, Simpson JF, Albers KM: Glial cell line-derived neurotrophic factor is a survival factor for isolectin B4-positive, but not vanilloid receptor 1-positive, neurons in the mouse. J Neurosci 2002;22:4057-4065.

72 McMahon SB, Priestley JV: Nociceptor plasticity; in Hunt S, Koltzenburg M (eds): The Neurobioloy of Pain. New York, Oxford University Press, 2005, pp 35-64.
73 Corness J, Shi TJ, Xu ZQ, Brulet P, Hökfelt T: Influence of leukemia inhibitory factor on galanin/GMAP and neuropeptide Y expression in mouse primary sensory neurons after axotomy. Exp Brain Res 1996;112:79-88.

-74 Leinninger GM, Backus C, Uhler MD, Lentz SI, Feldman EL: Phosphatidylinositol 3-kinase and Akt effectors mediate insulin-like growth factor-I neuroprotection in dorsal root ganglia neurons. FASEB J 2004; 18: 1544-1546.

75 Webster CR, Anwer MS: Role of the PI3K/ PKB signaling pathway in cAMP-mediated translocation of rat liver Ntcp. Am J Physiol 1999;277:G1165-G1172.

76 Salinas M, Lopez-Valdaliso R, Martin D, Alvarez $\mathrm{A}$, Cuadrado A: Inhibition of $\mathrm{PKB} /$ Akt1 by $\mathrm{C} 2$-ceramide involves activation of ceramide-activated protein phosphatase in PC12 cells. Mol Cell Neurosci 2000;15:156169.

77 Kim D, Kim S, Koh H, Yoon SO, Chung AS, Cho KS, Chung J: Akt/PKB promotes cancer cell invasion via increased motility and metalloproteinase production. FASEB J 2001; 15:1953-1962.

-78 Peres C, Yart A, Perret B, Salles JP, Raynal P: Modulation of phosphoinositide 3-kinase activation by cholesterol level suggests a novel positive role for lipid rafts in lysophosphatidic acid signalling. FEBS Lett 2003;534: 164-168.

79 Cantley LC: The phosphoinositide 3-kinase pathway. Science 2002;296:1655-1657.

80 Osaki M, Oshimura M, Ito H: PI3K-Akt pathway: its functions and alterations in human cancer. Apoptosis 2004;9:667-676.

$81 \mathrm{Hu}$ Y, Yao J, Liu Z, Liu X, Fu H, Ye K: Akt phosphorylates acinus and inhibits its proteolytic cleavage, preventing chromatin condensation. EMBO J 2005;24:3543-3554. 